Reprod. Nutr. Dévelop., 1986, 26 (1 B), 293-294.

\title{
Influence des protozoaires sur la dégradation des protéines mesurée in vitro et in sacco
}

K. USHIDA $\left({ }^{*}\right)$, J.-P. JOUANY

Laboratoire de la Digestion des Ruminants

I.N.R.A. Theix, 63122 Ceyrat, France.

(*) Department of Animal Science, Faculty of Agriculture, Kyoto University, Kyoto, 606 Japon.

Summary. Protozoa significantly increased in vitro protein degradability of 4 protein sources. In sacco, protozoa had a positive effect $(P<0.01)$ on potentially degradable insoluble protein fraction (b) and on rate of degradation (c). Our results showed that large Ophryoscolecidoe are particularly involved in rumen proteolysis.

Les protozoaires ciliés du rumen dégradent les protéines alimentaires (Kayouli et al., 1983) et réduisent l'apport de protéines microbiennes dans le duodénum du ruminant (Ushida et al., 1984). Ces résultats peuvent en partie expliquer l'influence parfois bénéfique de la défaunation sur la croissance du jeune ruminant. Le but de ce travail a été de préciser le rôle des ciliés et leur mode d'action dans la dégradation des protéines alimentaires dans le rumen.

Matériel et méthodes. Six moutons adultes de race Texel dont le rumen héberge une faune conventionnelle et 5 autres débarrassés de tout protozoaire (défaunés) ont été utilisés. Ils étaient tous porteurs d'une fistule permanente au niveau du rumen. Ils ont reçu une ration constituée de luzerne déshydratée condensée $(57 \%)$, de foin de prairie naturelle haché $(18 \%)$, d'orge aggloméré $(11 \%)$ et de paille de blé hachée $(14 \%)$, à raison de $1400 \mathrm{~g}$ de matière sèche par jour distribués en 2 repas $(8 \mathrm{~h}$ et $20 \mathrm{~h})$.

La dégradation in vitro des protéines de graine de lupin, tourteau d'arachide ou de soja, farine de poisson, a été déterminée à partir de la production d'azote ammoniacal $\left(\mathrm{N}-\mathrm{NH}_{3}\right)$, au cours d'incubations de $6 \mathrm{~h}$ en présence de jus et du contenu de rumen (Vérité et Démarquilly, 1978) provenant d'animaux faunés ou défaunés. Des mesures in sacco ont été réalisées avec 2 types de tissu de nylon (mailles de $50 \mu$ et $100 \mu$ ). Dix sachets $(5$ de $50 \mu$ et 5 de $100 \mu$ ) contenant chacun $3 \mathrm{~g}$ de tourteau de soja broyé à la grille de $3 \mathrm{~mm}$ ont été introduits ensemble dans le rumen de chaque mouton (fauné ou défauné) avant le repas du matin et enlevés $2,4,6,12$ et $24 \mathrm{~h}$ après. L'azote total dans les résidus des sachets a été dosé par la méthode de Kjeldahl. La cinétique de dégradation de l'azote a été assimilée au modèle mathématique : $P(t)=a+b\left(1-e^{-c t}\right)$. L'étude des effets (protozoaires - taille des mailles) et de leurs interactions a été effectuée par analyse de variance.

Résultats et discussion. La présence des protozoaires a entraîné une augmentation significative de la dégradation des protéines in vitro, de 10 à 11 points pour les aliments testés (tabl. 1).

Les résultats des mesures in sacco (tabl. 2) montrent que la présence de protozoaires et la taille des mailles du tissu n'ont pas eu d'effet sur la fraction immé- 
diatement solubilisée des protéines de tourteau de soja (a). Ces deux facteurs, ont, par contre, eu une action positive hautement significative $(P<0,01)$ à la fois sur la fraction des protéines insolubles potentiellement dégradables (b) et sur leur vitesse de dégradation (c), ce qui confirme les résultats de Kayouli et al. (1983). Les protozoaires n'interviennent donc pas, ou très peu, sur la dégradation des protéines solubles. L'action à l'égard de la fraction insoluble des protéines s'explique par le comportement alimentaire des protozoaires. Les particules solides qui ont été ingérées, sont en contact étroit avec les enzymes protéolytiques présentes dans le sac digestif des ciliés. Le rapport des concentrations entre enzymes et substrat est de ce fait plus élevé que dans le milieu liquide du rumen. Enfin, I'action cellulolytique des ciliés peut diminuer l'effet de barrière des parois cellulaires.

TABL. 1. - Influence de la présence des ciliés du rumen sur la dégradation in vitro de différentes sources protéiques (p. 100).

$(n=4)$

\begin{tabular}{cccccc}
\hline Inoculum & Lupin & Arachide & Soja & Farine poisson & S e m \\
\hline Défauné & 60,7 & 60,2 & 37,2 & 17,0 & 2,4 \\
Fauné & 70,9 & 71,7 & 47,6 & 27,9 & 2,5 \\
Signification & $P<0,01$ & $P<0,05$ & $P<0,05$ & $P<0,05$ & \\
\hline
\end{tabular}

TABL. 2. - Influence de la présence des ciliés du rumen sur la dégradation in sacco des protéines de soja.

\begin{tabular}{|c|c|c|c|c|c|c|c|c|}
\hline \multirow{2}{*}{$\frac{\text { Animaux }}{\text { Sachets (mailles) }}$} & \multicolumn{2}{|c|}{ Défaunés } & \multicolumn{2}{|c|}{ Faunés } & \multirow{2}{*}{ Sem } & \multicolumn{2}{|c|}{ Effets } & \multirow{2}{*}{ Interactions } \\
\hline & $50 \mu$ & $100 \mu$ & $50 \mu$ & $100 \mu$ & & " ciliés " & " mailles » & \\
\hline $\begin{array}{l}\text { a }(\%) \\
\text { b }(\%) \\
\text { c }\left(h^{-1}\right)\end{array}$ & $\begin{array}{r}14,4 \\
70,4 \\
8,7\end{array}$ & $\begin{array}{r}15,1 \\
79,8 \\
9,2\end{array}$ & $\begin{array}{r}16,8 \\
78,6 \\
8,7\end{array}$ & $\begin{array}{l}15,0 \\
85,0 \\
10,4\end{array}$ & $\begin{array}{l}0,79 \\
1,7 \\
0,22\end{array}$ & $\begin{array}{c}\text { N.S. } \\
* * \\
*\end{array}$ & $\begin{array}{c}\text { N.S. } \\
* * \\
* *\end{array}$ & $\begin{array}{l}\text { N.S. } \\
\text { N.S. } \\
*\end{array}$ \\
\hline
\end{tabular}

${ }^{*} \mathrm{P}<0,05 ;{ }^{*} \mathrm{P}<0,01 ; \mathrm{N} . \mathrm{S}$. = non significatif.

L'augmentation de la disparition de la fraction (b) des protéines consécutive à l'accroissement de la taille des mailles du tissu des sachets a été d'égale importance chez les animaux défaunés et faunés. Elle traduit donc une augmentation des pertes physiques. L'effet " protozoaires " sur la vitesse de dégradation (c) a été nul avec les sachets de $50 \mu$ alors qu'il a été significatif avec les sachets de $100 \mu$. Ce résultat, confirmé par la signification statistique de l'interaction des effets " protozoaires - taille des mailles " (tabl. 2), suggère que les Ophryoscolecidae de grande taille $(100 \mu)$ seraient particulièrement impliqués dans les phénomènes de protéolyse. La défaunation peut donc être un moyen d'augmenter le flux intestinal des protéines alimentaires non dégradées dans le rumen.

Kayouli C., Van Nevel C., Demeyer D., 1983. Effet de la défaunation du rumen sur la dégradabilité des protéines du soja mesurée in sacco. 4th int. Symp. on Protein metabolism and nutrition, Clermont-Ferrand (France), Vol II, Les colloques de I'I.N.R.A., I.N.R.A. Ed., 251-254.

Ushida K., Jouany J.-P., Lassalas B., Thiverid P., 1984. Protozoal contribution to nitrogen digestion in sheep. Can. J. anim. Sci, 64 (suppl.), 20-21.

Vérité R., Demarquilly C., 1978. Qualité des matières azotées des aliments pour Ruminants. In La Vache laitière. IXe Grenier de Theix, I.N.R.A. Publ. Versailles, 143-157. 